\section{IMAGE UNAVAILABLE FOR COPYRIGHT REASONS}

Cold spots: ISO's view of Whirlpool galaxy.

\section{Infrared images map 'invisible' matter}

Paris. The European Space Agency (ESA) last week released the first data from its Infrared Space Observatory (ISO), which was launched last November and is intended to reach the cool 'hidden' parts of the Universe other types of telescope cannot reach.

The ISO image (above) of the Whirlpool galaxy NGC 5194/5, for example, 20 million light years from Earth, shows bright spots in the spiral arms corresponding to warm dust clouds where stars are being formed and areas of cooler dust among and between the arms that represent the legacy of debris left by previous generations of stars.

"I'm absolutely delighted [with the first data]", says Catherine Cesarsky, the principle investigator for the telescope's camera. She points out that ISO marks an advance on previous infrared instruments - such as the joint UK/Dutch/US Infrared Astronomical Satellite, IRAS, which mapped 250,000 cosmic infrared sources in 1983 - in that it has better resolution and can measure radiation over the whole infrared spectrum. "We only had a rough picture before," says Cesarsky. "Now we can really do physics."

In particular, ISO's high sensitivity will allow astrophysicists to study the birth of stars and solar systems, while its ability to see cold 'invisible' matter will also help in the search for the Universe's 'missing mass' - the discrepancy between the mass of the Universe as estimated from gravitational calculations and that estimated from what can be seen in visible light.

ISO's successful entry into operation also makes Europe the apparent winner of a race between ESA and the US National Aeronautics and Space Administration (NASA) to fly a high performance infrared telescope, according to Cesarsky. She points out that although NASA began work on a similar telescope, SERTIF, before ESA, it has yet to complete the project.

The United States, she says, has now adopted an attitude of "if you can't beat them, join them". Indeed, both the United States and Japan have now reached agreement with ESA for the use of ISO. D. B.

\title{
French biomedical research 'needs more coordination'
}

Paris. France's secretary of state for research, François d'Aubert, has called for greater collaboration between those carrying out fundamental biomedical research and clinical researchers. This was one of three proposals contained in the government's first policy statement on research since d'Aubert took office last November, which was jointly presented to the cabinet last week by d'Aubert and Hervé Gaymard, secretary of state for health and social security.

The statement points out that although fundamental biomedical research is internationally competitive, France is relatively weak in clinical research and biotechnology. In particular, d'Aubert pointed out that only one French drug company ranks among the world's ten largest pharmaceutical groups, that no French-produced drug ranks among the top twenty best-selling drugs, and that the United Kingdom, for example, has four times as many biotechnology companies.

Closer collaboration between fundamental research and clinical research is one means to remedy this situation, according to d'Aubert, who called for increased research training in medical schools, greater mobility among clinical and basic researchers, and a reinforcement of existing joint structures between hospitals and public research bodies such as university teaching hospitals.

But observers are sceptical that these proposals amount to much more than good intentions and feel they are unlikely to lead to many concrete changes. "I am not taking this statement at all seriously," says one official from the national biomedical research agency, INSERM.

Indeed, d'Aubert's call for greater collaboration between clinical and basic research is seen by some as partly a reflection of the research ministry's desire to increase its control over the FFr300 million (US\$59 million) that the ministry of health takes from the hospital budget annually for clinical research. "If there is an urgent reform needed", quips one such critic, "it is for better cooperation between the ministries of health and research".

Research officials are nonetheless pleased with one aspect of the government's statement, its enthusiastic endorsement of the value of the so-called Instituts Fédératifs de Recherche (IFR). These are loose federations of laboratories that bring together scientists from research centres, universities and hospitals to create a critical mass in particular research areas at a single site.

Declan Butler

\section{Montagnier sets up AIDS research centre}

Paris. An 'Integrated Centre for Clinical and Biomedical AIDS Research' was this week formally inaugurated in the grounds of St Joseph's Hospital in Paris. It has been founded by Luc Montagnier of the Institut Pasteur and a member of the French group that discovered the human immunodeficiency virus (HIV) in the early 1980s.

The centre - whose FFr18 million (US\$3.6 million) construction costs were collected as part of a television campaign to raise funds for AIDS research - will have about 50 staff members and will bring together clinical and basic researchers at the same site. Its FFr8-million annual running costs will be met partly by the national AIDS research agency (ANRS) and further fundraising rounds, Montagnier says.

The centre's main clinical activity will be to study the association of various antivirals at a very early stage of infection by HIV. Whereas patients are usually treated only when their CD-4 levels fall below 200 cells per microlitre, the centre will treat patients with $\mathrm{CD}-4$ levels greater than 500 . The idea, says Montagnier, is to find out whether such treatment can delay the onset of AIDS, for example by reducing viral load.

Such an approach raises the ethical problem of treating otherwise healthy patients with drugs that generally have side-effects, admits Montagnier, who says all patients will be asked to give their informed consent to treatment. But he insists that the centre's main goal will be patient care. "It will be research in the service of the patient", says Montagnier, who argues that clinical research traditionally uses "patients in the service of research".

To evaluate the outcome of such early treatment, the centre will carry out detailed follow-up of individual patients using a variety of markers designed to measure, for example, cell death, the level of activation of the immune system, oxidative stress and cofactors - Montagnier has long argued that cofactors such as mycoplasmas increase the pathogenicity of AIDS. A "battery" of such markers is needed, he says, to establish which phenomena may be important in disease progression.

Basic research at the centre will focus on immunological aspects of the control of viral replication. This includes factors such as the role of oxidative stress in the development of the disease, and the mechanisms of protection among seropositive long-term 'survivors'. 